\title{
ORGANISATION AND IMMEDIATE CHALLENGES OF CIVIL PROTECTION IN BULGARIA
}

\author{
Andrey IVANOV, Ministry of Emergency Situations, \\ Director, National Service "Civil Protection"
}

\begin{abstract}
This article presents the highlights of the speech of Mr. Andrey Ivanov, Director of the Bulgarian National Service "Civil Protection," to the Second Scientific Conference on Protection of Population and Critical Infrastructure organized by the Center for National Security and Defense Research of the Bulgarian Academy of Sciences. The focus is on the National Programme for Disaster Protection of Bulgaria.
\end{abstract}

Keywords: Civil protection, prevention, planning for disaster protection.

In this article, it should be stressed that the system for population protection from disasters and accidents is part of the national security system of Bulgaria. The Bulgarian state protects the population in such cases in several ways:

- Through organizational activities;

- Through economic measures;

- Through social activities.

One of the highlights in the system for civil protection is prevention, which includes:

- Research, analysis, evaluation and prediction of disaster risks;

- Categorization of country's territory according to existing risks;

- $\quad$ Planning for disaster protection;

- Implementation of preventive measures to avoid or mitigate the effects of disasters, such as:

- Territorial, urban planning, construction and other technical measures;

- Establishing and maintaining of systems for monitoring, early warning and notification;

- Provision of collective and personal protective equipment; 


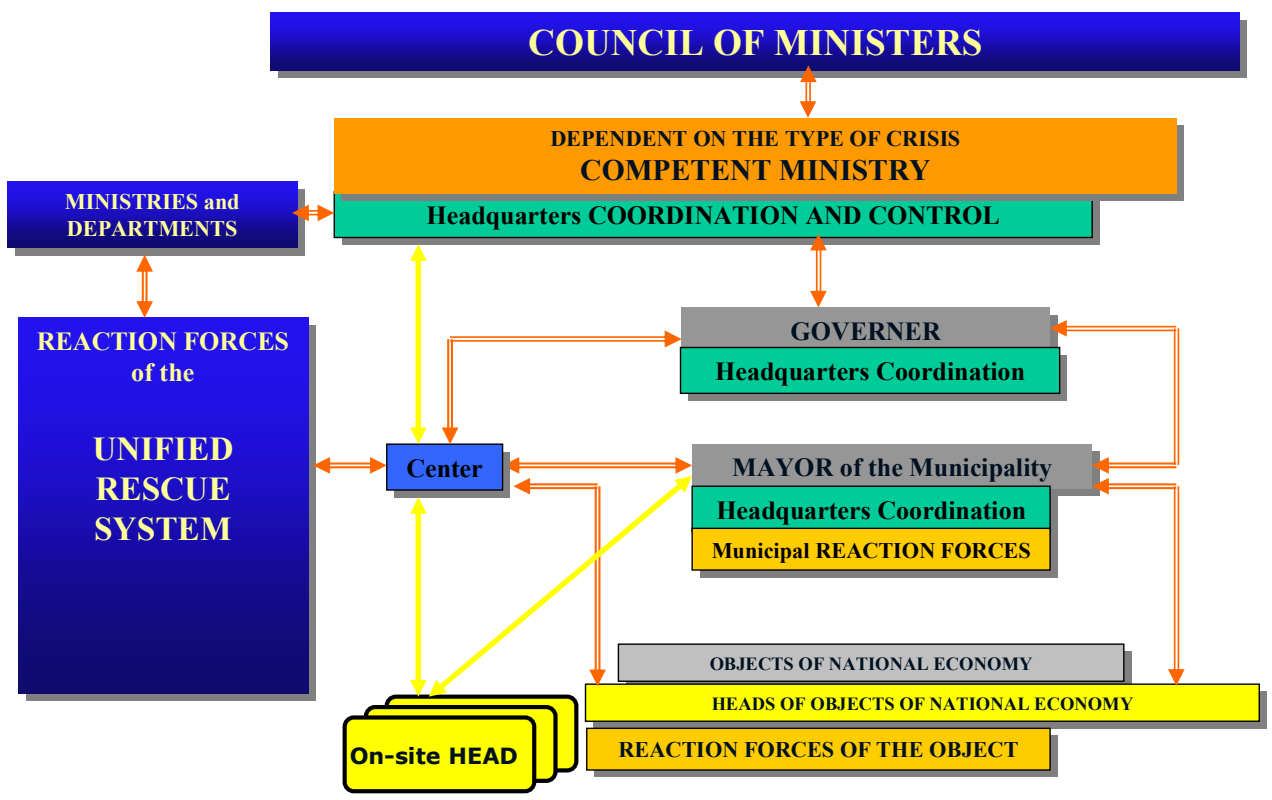

Figure 1: Crisis Management System.

- Training and preparation of central and territorial executive authorities, response forces and the population;

- $\quad$ Adopting a National Programme for Disaster Protection and annual plans for its implementation;

- Preventive control.

Planning for disaster protection is carried out at municipal, district and national levels.

The National Programme for Disaster Protection defines objectives, priorities and tasks for disaster protection for a period of five years. The program is funded by the state budget. Based on the national five-year program, ministries, districts and municipalities prepare and implement annual plans for the protection of the population.

Protection activities are carried out by departments, offices and other operating structures of:

- $\quad$ Ministries and departments;

- Municipalities;

- Commercial companies and individual businesses; 
- Centers for emergency medical care and other medical and health facilities;

- Non-profit organizations; and

- Armed Forces of the country.

Units, offices and other operational structures are components of the unified rescue system, while maintaining their institutional or organizational affiliation and designated functions and areas of activity.

In 2006, the Ministry of State Policy for Disaster Management started the development of a national map of critical infrastructure. This is an important step towards the preparation of the forthcoming Register of critical infrastructure at municipal, district and departmental level. 